\title{
Políticas públicas para o desenvolvimento sustentável brasileiro: o papel dos royalties do petróleo na institucionalização de uma política de preservação da biodiversidade
}

\section{Public Policies for Sustainable Development in Brazil: the Role of Oil Royalties in the Institutionalization of a Policy of Preserving Biodiversity}

\author{
Carlos José Saldanha MACHADO* \\ Rodrigo Machado VILANI** \\ Márcia CHAME**
}

\begin{abstract}
RESUMO
O objetivo desse trabalho é discutir a aplicação dos royalties do petróleo na conservação da biodiversidade brasileira como elemento de promoção do desenvolvimento sustentável. A perda de espécies e a redução de variedade genética são consequências diretas e/ou indiretas de ações antrópicas, tais como: desmatamento, expansão urbana, queima de combustíveis fósseis, entre outras. Partindo da concepção de que os royalties configuram uma compensação financeira, cuja gênese é a promoção de justiça intergeracional, realizamos uma análise do arcabouço legal em vigor para determinar a compatibilização desses recursos com a proteção da biodiversidade. Constatamos a permanência de uma lacuna na apropriação da perspectiva intergeracional, constitucionalmente estabelecida, tanto ao longo do processo legislativo como na prática das políticas públicas afins. Mesmo diante das várias opções existentes para a aplicação dos royalties do petróleo, concluímos defendendo a sua aplicação na conservação da biodiversidade enquanto patrimônio para as futuras gerações.
\end{abstract}

Palavras-chave: biodiversidade; royalties; justiça intergeracional; metodologia qualitativa; políticas públicas.

\footnotetext{
" Doutor em Antropologia Social (Université PARIS 5, Sciences Sociales Sorbonne). Pesquisador da Fundação Oswaldo Cruz (Fiocruz) e Professor dos Programas de Pós-Graduação em Biodiversidade e Saúde (PPGBS-IOC) da Fiocruz e em Meio Ambiente (Doutorado) da Universidade do Estado do Rio de Janeiro (PPG-MA/ UERJ).E-mail: saldanha@fiocruz.br

"* Doutor em Ciências do Meio Ambiente (UERJ). Professor da Universidade Federal do Estado do Rio de Janeiro (UNIRIO) e Professor do Mestrado em Planejamento Regional e Gestão de Cidades da Universidade Cândido Mendes (UCAM). E-mail: r vilani@yahoo.com.br

*** Doutora em Ciências Biológicas (UFRJ). Pesquisadora da Fundação Oswaldo Cruz (Fiocruz) e Coordenadora do Programa Institucional Biodiversidade \& Saúde da Fiocruz. E-mail: m-chame@globo.com
} 


\begin{abstract}
The aim of this paper is to discuss the application of oil royalties in biodiversity conservation in Brazil as part of promoting sustainable development. The loss of species and reduction of genetic variation are direct and/or indirect consequences of human actions such as deforestation, urban sprawl, burning fossil fuels, among others. Starting from the idea that the royalties make up a financial compensation whose genesis is the promotion of intergenerational justice, we performed an analysis of the legal framework in place to determine the compatibility of these resources with the protection of biodiversity. We notice that there is a gap in ownership of intergenerational perspective, constitutionally established, both along the legislative process and practice of related public policy. Even with the various options for the application of oil royalties, we conclude by defending its application in biodiversity conservation as heritage for future generations.
\end{abstract}

Keywords: biodiversity; royalties; intergenerational justice; qualitative methodology; public policies.

\section{Introdução}

Numa perspectiva histórica, pode-se dizer que os anos compreendidos entre o final da década de 1960 e começo dos anos 1970 tornaram-se o marco temporal da preocupação ambiental em âmbito global. A expressão meio ambiente emerge, abrangendo as relações entre o homem e o seu meio ambiente natural ou artificial. Amplia, portanto, o campo de estudo que havia sido proposto pela Ecologia, desde 1866, quando Ernst Haeckel referiu-se a essa ciência como o estudo da influência do ambiente sobre os animais, o qual, não necessariamente, precisaria levar em consideração a presença do homem. A partir das discussões do Clube de Roma, em 1968, e da I Conferência das Nações Unidas para o Desenvolvimento (UNCED), em Estocolmo, em 1972, inúmeros debates e conferências multilaterais se sucederam. Esse amplo debate, ainda em andamento, propôs diversos princípios e amplos objetivos de preservação e conservação ambiental voltados para aconciliação,de forma harmônica, com as finalidades econômicas das nações.

Desde então, conforme enfatizam Machado e Oliveira (2009a), mesmo ocorrendo uma ampliação do arcabouço legal de proteção do meio ambiente, fenômenos como "o processo de globalização, associado à intensificação e à velocidadedo deslocamento humano e de cargas pelos quatrocantos do mundo, contribuiu, sobremaneira, para a quebra de barreiras ecológicas" (p. 22).

Sob esta mesma perspectiva de análise, o Programa das Nações Unidas para o Meio Ambiente (PNUMA) destaca, em seu documento intitulado Rumo a uma Economia Verde, que:
Várias crises simultâneas iniciaram-se ou aceleraram-se durante a última década: crises climáticas, de biodiversidade, combustível, alimentos, água, e mais recentemente no sistema financeiro e econômico como um todo. A aceleração de emissões de gases de efeito estufa indica uma ameaça crescente de mudanças climáticas descontroladas, com consequências potencialmente desastrosas para a humanidade. (PNUMA, 2011, p. 1).

Em conjunto, essas crises colocam em risco a existência do próprio ser humano no planeta ao destruir a base material de sustentação econômica e social, respectivamente, os recursos naturais (em termos quantitativos) e o ambiente ecologicamente equilibrado (tomado sob a perspectiva da qualidade de vida da população).

A perda de qualidade ambiental e a redução do estoque de recursos naturais requerem um novo direcionamento na agenda de temas e problemas a serem discutidos e institucionalizados por meio da formulação e/ou do aprimoramento de políticas públicas. Para exemplificar o problema a ser enfrentado, tratamos da erosão dos recursos genéticos do planeta, tanto pela extinção de espécies como pela redução de sua diversidade genética, ocasionada pela supressão de habitats e espécimes. Moraes (2010, p. 6) justifica que a "perda de biodiversidade tornou-se uma questão central que mobiliza tanto a comunidade científica quanto o governode diversos países, principalmente os de regiões tropicais".

Assim sendo, enquanto líder da lista dos 17 países detentores da maior diversidade biológica do planeta (SZPILMAN, 1998), é preciso analisar se o Brasil dispõe de um arcabouço institucional-legal competente para gerir esse patrimônio de aproximadamente $13 \%$ de toda a biota do planeta (LEWINSOHN; PRADO, 2005). Ademais, é 
preciso reconhecer como podem ser criadas e mantidas iniciativas positivas de conservação da diversidade biológica de um país cujo pluralismo cultural também impressiona. São cerca de 230 etnias indígenas, que totalizam, aproximadamente, 800 mil pessoas espalhadas pelo país. A grande maioria das etnias indígenas $(96,61 \%)$ vive na floresta amazônica, enquanto o restante habita predominantemente áreas urbanas, ocupando cerca de 13\% do território nacional (ISA, 2010; WESSENDORF, 2008).

Como forma de colaborar para esse debate, procuramos conciliar esses ideais com o objetivo de promoção da justiça intergeracional que se encontra na gênese dos royalties, de maneira geral, e, especificamente, daqueles provenientes da atividade petrolífera. Isso porque se discute atualmente no país a repartição desses recursos sem, contudo, aprofundar os critérios de destinação dos mesmos para que se assegure o direito das futuras gerações, aviltado pelo esgotamento dos recursos no presente.

A matéria, entretanto, não é de solução simples. Em notícia dada pela própria Câmara dos Deputados, seu atual presidente (2011-2012), Dep. Marco Maia, afirmou que nunca haverá consenso para a questão relacionada à distribuição dos royalties, "devido à complexidade e [a]o grau de polêmica que possui” (OLIVEIRA, 2011). Ademais, conforme noticiado pelo jornal $O$ Globo, a controvérsia quanto à nova proposta de divisão de royalties ainda se prolongará na Câmara dos Deputados; entretanto, consoante Kaercher (apud JUNGBLUT et al., 2011, p. 32), "se o objetivo é alcançar uma equidade distributiva, quem deveria abrir mão dos royalties e PEs [Participações Especiais] nos campos a serem licitados seria a União".

Procurando, então, trazer elementos para a definição de critérios na destinação dos royalties e para a garantia da responsabilidade intergeracional por meio da conservação da diversidade biológica, o trabalho trata, inicialmente, da questão relacionada à destinação dos royalties do petróleo. Em seguida, realiza uma breve análise dos princípios estruturantes desse trabalho - desenvolvimento sustentável e responsabilidade intergeracional. Para contextualização dos principais aspectos relacionados à biodiversidade, procedemos com apontamentos gerais quanto aos impactos das ações antrópicas sobre os recursos genéticos. Definido o objeto de estudo, legal, institucional e conceitualmente, realizamos, em seguida, a partir da Convenção da Diversidade Biológica (CDB), as propostas para o fortalecimento das medidas de proteção da biodiversidade brasileira. Por fim, tecemos considerações gerais acerca dos pontos de aproximação e distanciamento entre as previsões legais e constitucionais e a realidade de prática pública nacional no alcance de um modelo de desenvolvimento que se proponha sustentável. As descrições e análises desse artigo basearam-se em informações levantadas por meio de uma metodologia qualitativa estruturada em torno da técnica de leitura de fontes secundárias (dispositivos jurídicos diversos, artigos científicos, capítulos de livros, livros, relatórios, sites institucionais e governamentais).

\section{Destinação dos royalties do petróleo}

Inicialmente, destacamos que os royalties não são as únicas compensações governamentais, conforme dispõe o art. 45 da Lei 9478/97 (Lei do Petróleo), que ainda prevê: a) o bônus de assinatura; b) a participação especial; c) o pagamento pela ocupação ou retenção de área. Ao lado da participação especial, configuram-se de maior importância por estarem vinculados à produção petrolífera.

Assim sendo,

Os royalties constituem uma compensação financeira mensal à União incidente sobre o valor total da produção de óleo e gás. Em geral, a alíquota deste tributo é de 10\% sobre o valor da produção, avaliada de acordo com um preço de referência calculado com base em uma cesta de tipos internacionais de petróleo ou gás. A ANP pode estabelecer em edital de licitação a redução, em até 5 pontos percentuais, da alíquota deste tributo, se julgar que as condições de produção e os riscos geológicos justifiquem tal medida. Os recursos arrecadados via royalties são divididos entre os Estados e os Municípios produtores, o Tesouro Nacional e os Ministérios da Ciência e Tecnologia e da Marinha (POSTALI, 2009, p. 212).

A legislação nacional esclarece esta conceituação, afirmando que os royalties "constituem compensação financeira devida pelos concessionários de exploração e produção de petróleo ou gás natural" (art. 11 do Decreto 2.705/1998). Em relação a esta conceituação, Freitas (2009, p. 6) traz duas interpretações quanto ao seu alcance. Primeiramente, "trata do pagamento de uma renda no sentido econômico (ou ricardiano), em virtude da propriedade de um fator de produção não reproduzível." Por outro lado, uma segunda leitura refere-se aos royalties como compensação pelos impactos negativos da indústria petrolífera. Importa 
reconhecer que, pelo primeiro entendimento, temos a concentração dos royalties na União, em ressarcimento pelo esgotamento de um recurso de sua propriedade, enquanto que a segunda construção descentralizaria os recursos, direcionando-os aos municípios e Estados produtores, que suportam os impactos ambientais, econômicos e sociais da exploração dos recursos energéticos fósseis (FREITAS, 2009, p. 7).

Essa "confusão interpretativa" é tratada por autores como Leal e Serra (2003, p. 163), que alertam para que essa compensação não seja relacionada "aos impactos negativos do adensamento causados pela acelerada dinâmica de crescimento das áreas produtoras de petróleo e gás natural". Isso porque essa condição, inerente ao determinismo físico das reservas, aumenta, por exemplo, a circulação de renda e a arrecadação tributária. É neste sentido que os autores argumentam que sua função é a de "equacionar um problema de justiça intergeracional", o que significa a compensação pelo esgotamento de recursos não renováveis, o que implica em "atrelar sua aplicação a investimentos pró-diversificação produtiva” (LEAL; SERRA, 2003, p. 163).

Entretanto, nos mercados atuais, prepondera a ausência da preocupação com as gerações futuras (LEIS, 1999, p. 160), em flagrante descompasso, como veremos na próxima seção, com os princípios constitucionais do desenvolvimento sustentável e da responsabilidade intergeracional. Isso se evidencia em relação aos combustíveis fósseis porque "o preço do petróleo ou do carvão não considera o fato de estar sendo consumido recurso natural não renovável" (MONTIBELLER FILHO, 2004, p. 129). E não só pelo mercado, como pela própria questão da Administração Pública, a qual tende a reproduzir esses efeitos adversos, como aponta Serra (2007, p. 96), em relação ao uso dos royalties pelo Ministério de Ciência e Tecnologia, definido pelo art. 49, I, “d” e II, “f”, da Lei no 9.478/971', que, "antes de guiar-se pelo princípio da promoção da justiça intergeracional, segue o sentido oposto, contribuindo para adensar a própria cadeia produtiva do petróleo e, quiçá, intensificando o próprio ritmo de exploração das jazidas de petróleo e gás".

Ganha relevo, portanto, no momento em que são discutidas propostas governamentais para a revisão dos critérios de partilha dos royalties do petróleo da chamada camada pré-sal, perquirir a adequação da aplicação desses recursos em consonância com a gênese daquela compensação financeira. Em outras palavras, o debate não pode ser conduzido apenas em razão da necessidade de manutenção das condições de sustentação financeira dos diferentes entes federados.

Cumpre destacar, brevemente, que a "descoberta" da camada do pré-sal se deu a partir de poços de petróleo perfurados na Bacia de Santos em 2004, até que, em 2006, foram confirmados grandes reservatórios de petróleo e gás natural a uma profundidade de $7.600 \mathrm{~m}$, a partir do nível do mar (PETROBRAS, 2010). O descobrimento dessa nova fronteira exploratória deu início a um processo de revisão da legislação regulatória das atividades de petróleo e gás natural, que culminou com a divulgação, em 31 de agosto de 2009, do "novo marco regulatório", sob o slogan "Pré-sal patrimônio da União, riqueza do povo e futuro do Brasil". A elaboração do novo marco regulatório ficou a cargo de uma Comissão Interministerial (CI), especialmente instituída "com a finalidade de estudar e propor as alterações necessárias à legislação, no que se refere à exploração e à produção de petróleo e gás natural nas novas províncias petrolíferas descobertas em área denominada Pré-Sal" (Decreto sem número, de 17 de julho de 2008). Um traço característico da CI é que não há previsão de representação do Ministério do Meio Ambiente, apesar de se tratar da exploração de recurso natural para os quais será exigido licenciamento ambiental e, assim sendo, devendo ser analisados os impactos ambientais da exploração do pré-sal.

Não nos parece ser demasiado acentuar que se trata aqui de um recurso esgotável e por mais que novas desco-

\footnotetext{
1 Art. 49. A parcela do valor do royalty que exceder a cinco por cento da produção terá a seguinte distribuição:

I - quando a lavra ocorrer em terra ou em lagos, rios, ilhas fluviais e lacustres:

$[\ldots]$

d) $25 \%$ (vinte e cinco por cento) ao Ministério da Ciência e Tecnologia para financiar programas de amparo à pesquisa científica e ao desenvolvimento tecnológico aplicados à indústria do petróleo, do gás natural, dos biocombustíveis e à indústria petroquímica de primeira e segunda geração, bem como para programas de mesma natureza que tenham por finalidade a prevenção e a recuperação de danos causados ao meio ambiente por essas indústrias;

II - quando a lavra ocorrer na plataforma continental:

$[\ldots]$

f) $25 \%$ (vinte e cinco por cento) ao Ministério da Ciência e Tecnologia para financiar programas de amparo à pesquisa científica e ao desenvolvimento tecnológico aplicados à indústria do petróleo, do gás natural, dos biocombustíveis e à indústria petroquímica de primeira e segunda geração, bem como para programas de mesma natureza que tenham por finalidade a prevenção e a recuperação de danos causados ao meio ambiente por essas indústrias.
} 
bertas prolonguem o estoque das reservas do país estaremos diante de um adiamento da escassez do petróleo e do gás natural. Neste sentido, antes que se comprovem todas as expectativas das reservas do pré-sal, importa destacar apontamento do Ministério de Minas e Energia para definir o panorama energético brasileiro (BRASIL, 2007, p. 40):

Utilizando-se o Método da Curva de Hubbert, verificou-se que em 2010 o Brasil poderá exportar em torno de $20 \%$ da sua produção, que atingirá o seu pico em 2018. Em 2025, por outro lado, o país voltará a ser dependente da importação de óleo bruto para atender à demanda interna. Em decorrência do possível excedente na produção de petróleo do país, vale a discussão estratégica sobre a escolha entre exportação do óleo bruto ou de seus derivados. Da mesma forma, é preciso planejamento para que uma nova situação de dependência de petróleo não comprometa a segurança energética do país.

Assim, a conciliação entre crescimento econômico e conservação ambiental requer critérios positivados com clareza e objetividade, pois,

Não perceber a fortíssima presença das diferentes pressões econômicas nas questões relativas ao meio ambiente, em minha opinião, significa permitir que elas ajam sem controle e em claro prejuízo ao meio ambiente e à qualidade de vida. De fato, é extremamente necessário que o tratamento econômico das questões ambientais seja feito sem preconceito e abertamente, pois a renúncia em empreender tal abordagem não implica que a problemática econômica se retire das questões referentes ao meio ambiente; ao contrário, implica que a perspectiva econômica se apresente de forma imediatista e, destarte, sem os necessários cuidados ambientais, como tem sido comprovado diariamente. Aliás, o jurista brasileiro não se pode furtar a enfrentar o espinhoso tema das relações entre economia e ambiente, vez que, em sede constitucional, a matéria está plenamente caracterizada como de natureza econômica, embora não se restrinja a isso (ANTUNES, 2002, p. 201).

A Constituição Federal relaciona expressamente a ordem econômica e a conservação ambiental que, por sua vez, contém a questão da proteção do patrimônio genético. Destarte, em se tratando da questão da diversidade biológica não desconhecemos que, somada aos aspectos econômicos e ambientais, a mesma perpassa e é atravessada pela discussão social. Nesse sentido, reconhecemos que a "raiz da degradação do meio ambiente" é "a mesma da desigualdade social" (ACSELRAD, 2001, p. 34) e, assim, apesar de "ecologicamente interligado, o mundo é socialmente fragmentado", devido à preponderância da "desigualdade ao acesso e uso da base material da existência" (RIBEIRO, 2003, p. 405). Desse modo,

[...] para os muitos mundos em que se divide o planeta pela desigualdade social entre classes e regiões, a questão da pressão agregada sobre os recursos ambientais é atravessada pelas temáticas da desigualdade distributiva, da dependência financeira, da desigualdade no controle dos mecanismos de comércio e dos fluxos de tecnologia. Tais mecanismos se originam na desigual correlação de forças econômicas e políticas que regulam o acesso de classes e países à base material do desenvolvimento. Dessa desigualdade nascem e, ao mesmo tempo, circularmente, a ela alimentam (ACSELRAD, 2001, p. 34).

A complexidade do tema requer amplo debate social, político e científico e, ainda que haja longo processo de solidificação dos critérios a serem adotados, o pressuposto básico de que os royalties "têm como função equacionar um problema de justiça intergeracional" (LEAL; SERRA, 2003, p. 163) deve restar incontroverso.Para alcançar esse objetivo, torna-se imprescindível e inadiável a correção no direcionamento dos recursos obtidos em troca do esgotamento do petróleo e do gás natural sob a forma de "investimentos que gerem riqueza alternativa para substituir a riqueza exaurida" (PIQUET, 2003, p. 231).

Entretanto, de acordo com as conclusões de Pacheco (2005, p. 6), os gastos com os royalties estão sendo direcionados para a "ampliação da oferta de bens e serviços públicos, como se fossem recursos tributários. Parece não haver uma preocupação em atrelar sua aplicação a investimentos pró-diversificação da base econômica produtiva." O pesquisador ressalta a importância da diversificação frente à oferta finita desses recursos naturais e, por desdobramento lógico, das compensações financeiras. "Assim, apesar de estarem contribuindo para a melhoria do bem-estar das gerações presentes, não está claro em que medida as despesas financiadas com os recursos dos royalties irão beneficiar as gerações futuras" (PACHECO, 2005, p. 6).

A título de consolidação deste primeiro elemento, procuramos entender como o novo marco regulatório con- 
tribui para o direito das gerações futuras, especificamente, por meio da proteção ao patrimônio genético brasileiro. Da nova legislação ${ }^{2}$ da atividade petrolífera interessa, ao objeto de nosso estudo, o Fundo Socialproposto como instrumento de natureza contábil e financeira com a finalidade de constituir fonte de recursos para o desenvolvimento social e regional, na forma de programas e projetos nas áreas de combate à pobreza e de desenvolvimento: I - da educação; II - da cultura; III - do esporte; IV - da saúde pública; V da ciência e tecnologia; VI - do meio ambiente; e, VII - de mitigação e adaptação às mudanças climáticas (art. 47, caput, Lei 12.351/2010).

No entanto, apesar de Estados e partidos políticos viverem desde já uma espécie de expectativa de herança do pré-sal, que não tem previsão de início da produção comercial antes de 2015, alternativas de sustentabilidade ambiental permanecem fora do discurso oficial. E essa tem sido a preocupação com o novo marco regulatório: a ausência de critérios ambientais e de vinculação com um projeto de desenvolvimento nacional sustentável. Inexiste na agenda pública um programa efetivamente elaborado para assegurar o uso dos recursos provenientes da exploração do petróleo de forma a promover a justiça intergeracional. Assim, como se torna patente pela da leitura do art. 47, VI, da Lei 12.351/2010, no qual meio ambiente é mencionado de maneira genérica, sem regulamentação específica que particularize as áreas a serem atendidas.

Entendemos que particularizar os temas fortalece o alcance dos seus objetivos. Em relação ao inciso VI, que menciona o meio ambiente, programas e projetos relacionados à conservação da biodiversidade devem ser financiados pelo Fundo Social, em conformidade com a finalidade de promoção de justiça intergeracional.

Com o intuito de dar maior embasamento ao nosso entendimento da questão, traçaremos, na próxima seção, a partir das disposições do texto constitucional, algumas diretrizes básicas voltadas para o fortalecimento das discussões acerca da apropriação pela legislação infraconstitucional dos princípios do desenvolvimento sustentável e da responsabilidade intergeracional instituídos pela Carta Magna.

\section{Desenvolvimento sustentável e responsabilidade intergeracional}

A Constituição Federal (CF) apregoa o desenvolvimento nacional como objetivo fundamental do Estado (art. $3^{\circ}$, II, CF), devendo, entretanto, ser entendido a partir da harmonização com a Ordem Econômica (art. 170 e ss., CF), onde se estabelece que o crescimento econômico (art. 170, caput) atenderá aos princípios da defesa do meio ambiente (art. 170, VI, CF) e da redução das desigualdades regionais e sociais (art. 170, VII, CF). Temos, assim, a tríade básica do chamado desenvolvimento sustentável que, entretanto, comumente tem suprimida sua perspectiva temporal, constitucionalmente prevista pela responsabilidade intergeracional encerrada no art. 225, caput, in fine. Portanto, o desenvolvimento nacional qualificado como sustentável possui quatro elementos constituintes: a) crescimento econômico; b) justiça social; c) defesa do meio ambiente; d) responsabilidade intergeracional.

Como nos lembram May e Motta (1994), “embora existam inúmeras formas de se definir desenvolvimento sustentável, o que na verdade está se discutindo é a crescente preocupação com os atuais padrões de crescimento econômico que podem resultar na inviabilidade da vida humana na Terra" (p. 1).

Diante deste fato, é necessário apontar a origem da expressão desenvolvimento sustentável. Veiga (2006, p. 190) indica ter sido empregada "pela primeira vez em agosto de 1979 em Estocolmo, no Simpósio das Nações Unidas sobre as Inter-Relações entre Recursos, Ambiente e Desenvolvimento, no qual W. Burger apresentou um texto intitulado A busca de padrões sustentáveis de desenvolvimento". Por outro lado, parte da literatura (ROMEIRO, 2003, p. 5; LEIS, 1999, p. 146) aponta o surgimento do termo a partir do ecodesenvolvimento, cunhado na década de 1970, como proposta alternativa ao crescimento meramente econômico, e que teve em Ignacy Sachs seu principal teórico. Há, ainda, indicação de que tenha surgido em 1983, durante Assembleia Geral da ONU, que dava início às discussões que culminariam, três anos mais tarde, no Relatório Nosso Futuro Comum (OSORIO; LOBATO; CASTILLO, 2005, p. 502). Enfim, o único consenso em relação ao surgimento do termo desenvolvimento sustentável é que apenas em ${ }^{2}$ Lei 12.276/2010 - estabelece a cessão onerosa em favor da Petrobras; Lei 12.304/2010 - cria a Empresa Brasileira de Administração de Petróleo e Gás Natural
S.A.; Lei 12.351/2010 - institui o regime de partilha e cria o Fundo Social. 
1987, no Relatório Nosso Futuro Comum ou Relatório Brundtland, em homenagem à presidente da Comissão Mundial Sobre Meio Ambiente e Desenvolvimento, Gro Harlem Brundtland, cunhou-se o conceito, hoje utilizado mundialmente: "Desenvolvimento sustentável é o desenvolvimento que alcança as necessidades do presente sem comprometer a habilidade das gerações futuras de atender suas próprias necessidades" (UNITED NATIONS, 2008).

Apesar da crescente literatura sobre desenvolvimento sustentável, não se chegou a uma conceituação doutrinária consensual, pelo contrário, são apontadas críticas pelo seu caráter meramente teórico, vago e muito amplo e, assim, com pouca orientação prática (FARZIN, 2002, p. 1; LENZI, 2006, p. 92). Característica que o torna maleável ao uso segundo diferentes interesses, condição que acabou por banalizar a sustentabilidade, aprofundando a distância entre o discurso e a eficácia de políticas ambientais, conforme advertem Fonseca e Bursztyn (2009, p. 19).

Assim sendo, antes de escamotear ingenuamente os óbices à concretização de um modelo de desenvolvimento que se proponhasocialmentejusto e economicamentedistributivo para as presentes e futuras gerações, reconhecemos as "tensões e ambiguidades" do conceito (LEIS, 1999, p. 156). Contudo, procuramosextrapolar, dentro dos limites deste trabalho, as críticas sobre a impossibilidade de um desenvolvimento capitalista sustentável para contribuir com a construção de um modelo (MACHADO, 2012), ainda que teórico, passível de suprir o "silêncio conceitual" (CARNEIRO, 2005, p. 32) existente, in casu, entre a produção capitalista e a diversidade biológica.

Dotado de caminho menos sinuoso, o princípio da responsabilidade intergeracional teve sua concepção no Direito Internacional, tendo por finalidade assegurar que cada geração receba o planeta em fideicomisso para as futuras gerações, segundo explicação de Carvalho (2005, p. 376). Assim sendo, conceitualmente desenvolvimento sustentável e responsabilidade intergeracional se complementam, mas não se confundem. A Declaração de Estocolmo (1972) previa, em seu Princípio 1, que o homem tem o direito fundamental à liberdade, à igualdade e ao desfrute de condições de vida adequadas em um meio ambiente de qualidade tal que lhe permita levar uma vida digna e gozar de bem-estar, tendo a solene obrigação de proteger e melhorar o meio ambiente para as gerações presentes e futuras.

Desta forma, a responsabilidade intergeracional representa a herança entre as gerações que o desenvolvimento sustentável procura harmonizar a partir dos aspectos econômicos, sociais e ambientais intrageracionais.

Estamos, assim, diante de uma relação fundada sobre a dimensão temporal (KISS; SHELTON, 2007, p. 106): passado, presente e futuro. A partir da reflexão de Carneiro (2003, p. 55) sobre o tema, extrapolamos a proposta do autor por entender que às gerações presentes se impõe a "obrigação especial, enquanto tutores ou curadores do planeta" (KISS; SHELTON, 2007, p. 106) de preservar e aprimorar as condições ambientais, herdadas das gerações passadas, objetivando perpetuar a diversidade biológica.

Analisados a perspectiva constitucional e os aspectos teóricos do desenvolvimento sustentável, somos da opinião que o ordenamento jurídico, em plena vigência no Brasil, baseia-se no "duplo imperativo ético" da sustentabilidade ambiental, firmado por Veiga (2006, p. 171), sobre uma "solidariedade sincrônica com a geração atual e [outra] diacrônica com as gerações futuras".

Da perspectiva apontada emerge o aspecto ético envolvido na questão intergeracional (TRINDADE, 1993, p. 218): "a dimensão temporal de longo prazo, desvendada pelo próprio termo humanidade, a abranger tanto as gerações presentes quanto as futuras, e a revelar o vínculo com o âmbito dos direitos humanos (a busca da sobrevivência)".

Daí, a nosso ver, a emergência de discutirmos o princípio da proibição do retrocesso cujo "conteúdo impeditivo [...] torna possível brecar planos políticos que enfraqueçam os direitos fundamentais" (ALMEIDA, 2007, p. 123).

Dito de outro modo, a Constituição não tem somente a tarefa de apontar para o futuro. Tem, igualmente, a relevante função de proteger os direitos já conquistados. Desse modo, mediante a utilização da principiologia constitucional (explícita ou implícita), é possível combater alterações feitas por maiorias políticas eventuais, que, legislando na contramão da programaticidade constitucional, retiram (ou tentam retirar) conquistas da sociedade (STRECK, 2003, p. 53).

Almeida (2007, p. 119) ressalva a ausência de ampla aplicação do princípio e o define como aquele caracterizado "pela impossibilidade de redução dosdireitos sociais amparados na Constituição, garantindo ao cidadão o acúmulo de patrimônio jurídico".

[...] princípio da proibição do retrocesso ecológico, que resulta, em termos universais, do princípio da 
maximização de eficácia de todas as normas de direitos fundamentais, como ocorre aqui, no Brasil, vez que o art. $5^{\circ}, \S 1^{\circ}$, de nossa Carta Magna impõe a proteção efetiva dos direitos fundamentais não apenas contra a atuação do poder de reforma constitucional (em combinação com o art. 60, que dispõe a respeito dos limites formais e materiais às emendas da Constituição), mas também contra o legislador ordinário e demais órgãos estatais (PRUDENTE, 2010, p. 39).

Enquanto direito fundamental da pessoa humana, o direito ao meio ambiente ecologicamente equilibrado, ao qual se subsume o direito de acesso das futuras gerações ao patrimônio genético (art. 225, caput, in fine $\mathrm{c} / \mathrm{c} \S 1^{\circ}$, II, $\mathrm{CF}$ ), está resguardado contra eventuais intervenções políticas que possam esvaziar seu conteúdo protetivo. Destarte, temos fortalecido o instrumentário jurídico de proteção ao ambiente entendido em sua totalidade.

Contudo, a realidade nos impõe reconhecer vasto campo de atuação do princípio do não retrocesso ecológico, como diante da omissão que se vislumbra diante da constatação de que "as condições para que o patrimônio biológico brasileiro seja efetivamente utilizado de forma sustentável e socialmente justa não estão garantidas no atual arcabouço legal existente no País" (CAMARGO; CAPOBIANCO; OLIVEIRA, 2002, p. 246). Senão vejamos:

O reconhecimento pela Convenção da Biodiversidade dos países sobre seus recursos genéticos significa tão somente o direito de negociá-los, não de subtraí-los às regras do mercado tais como definidas pela Organização Mundial do Comércio (OMC).

A evolução do trabalho legislativo no Brasil, nestes últimos anos, parece reforçar, salvo raras exceções, essa tendência. A Lei das Patentes (Lei n. ${ }^{\circ}$ 9.279/96), que regula a propriedade industrial, e a Lei de Cultivares (Lei no 9.456/97), que cria direitos de propriedade intelectual sobre variedades comerciais de plantas, reforçaram a submissão dos recursos biológicos e genéticos à lógica do mercado (LEROY; PACHECO, 2002, p. 250).
Miozzo (2011, p. 5) reforça que, diante de uma prestação positiva do Estado, como o processo legislativo e mesmo do poder de polícia, concorre "uma imposição de abstenção", representada, por um lado, pela "obrigação de concretizar um direito" e, por outro, "de não tomar medidas retrocessivas que atentem contra as conquistas já atingidas em termos de legislação".

Os primeiros passos para a regulamentação do setor no país se deram por meio do Projeto de Lei do Senado, $\mathrm{n}^{\circ}$ 306/1995, de autoria da Senadora Marina Silva, que tinha por objeto a definição dos instrumentos de controle do acesso aos recursos genéticos, mas acabou arquivado em abril de 2007 (SENADO FEDERAL, 2011). Após a elaboração de outros projetos de lei, atualmente o tema possui regulação na Medida Provisória 2.186-16/01 e, como autoridade instituída, o Conselho de Gestão do Patrimônio Genético (CGEN) para tratar da gestão do patrimônio genético e do conhecimento tradicional associado (MACHADO; GODINHO, 2011). Medidas Provisórias em nosso ordenamento jurídico são atos normativos com força de lei, que podem ser adotados pelo Presidente da República em casos de relevância e urgência. $O$ caráter provisório da legislação que regula o tema perdura há dez anos, ainda sem data prevista para a edição da lei que a substitua. ${ }^{3}$

Minaré (2008) destaca, contudo, que a revisão do marco legal encontra-se presa na morosidade do processo legislativo e, com isso, acentuam-se os pontos controversos vigentes, entre os quais se destacam como "as principais dificuldades do setor [aquelas] relacionadas à lentidão do procedimento administrativo dos processos no Conselho de Gestão do Patrimônio Genético - CGEN - e aos elevados custos da operação". O autor, entretanto, defende que a proposta que se encontra em meio a um longo período de consulta pública não trará as soluções pretendidas:

A proposta que o governo disponibilizou para consulta pública no final de 2007, e que ainda continua em consulta, ostenta 142 artigos, 104 a mais do que a MP $\mathrm{n}^{\circ}$. 2.186-16/01, e pouca expectativa de mudanças para melhor. O problema, muito semelhante ao que ocorre

\footnotetext{
${ }^{3}$ Em 2003, a Câmara Técnica Legislativa do Conselho de Gestão do Patrimônio Genético (CGEN) coordenou a elaboração de um anteprojeto de lei com o objetivo de substituir a Medida Provisória e regulamentar o Tratado Internacional sobre Recursos Fitogenéticos para a Alimentação e a Agricultura, aprovado pela Organização das Nações Unidas para a Alimentação e Agricultura, em 2001, e ratificado pelo Brasil em 2006. O APL foi encaminhado à Casa Civil e, após alguns debates, foi submetido a consulta pública em 2007. Atualmente o referido anteprojeto de lei se encontra na Casa Civil à espera de ser encaminhado pela Presidente da República ao Congresso Nacional. Para uma análise comparativa entre este anteprojeto de lei elaborado pelo CGEN, que foi submetido a consulta pública pela Casa Civil, e a Medida Provisória 2.186-16/01, apontando os avanços obtidos e os pontos que ainda devem ser aperfeiçoados, ver Godinho e Machado (2011)
} 
no campo dos transgênicos, é mais ideológico do que normativo. De nada vai adiantar mudar a lei se o pensamento equivocado que norteou a administração do CGEN nos últimos anos permanecer. O emaranhado administrativo continuará existindo nos processos de emissão de licença, realização de cadastros e análise de relatórios, figuras administrativas que aparecem na proposta de lei em consulta (MINARÉ, 2008).

Ademais, consoante reflexão de Azevedo (2005, p. 25), para que uma nova regulamentação atenda ao interesse público e científico, especialmente no que tange à proteção e ao uso sustentável da biodiversidade e dos conhecimentos tradicionais associados, será necessária a "representação de determinados setores da sociedade, buscando construir pontes de entendimento entre todas as partes envolvidas e não defendendo corporativamente interesses específicos".

Portanto, diante do fato de não haver uma legislação competente adequada para a regulamentação do acesso aos recursos genéticos (MACHADO; GODINHO, 2011; VARELLA, 1997, p. 139), que poderia, entre outros aspectos, preservar ecossistemas naturais, proteger comunidades tradicionais, desenvolver a ciência e tecnologia no país, enfim, promovendo o desenvolvimento sustentável, o ordenamento jurídico em vigor pode sofrer retrocesso em se tratando das proteções constitucionalmente previstas para o patrimônio genético brasileiro.

Fato é que hoje há o desafio de se acordar, em uma única proposta, a reformulação do instrumento legal a ser apresentado pelo governo à sociedade. Esta deverá unificar os múltiplos interesses dos setores públicos e privados e da sociedade civil e, mais que tudo, estabelecer modus operandi simplificado e direcionado à ação regulatória dos acessos à biodiversidade e ao conhecimento tradicional a ela associado, garantindo a repartição de benefícios e não somente a avaliação de mérito dos projetos.

Cabe ressaltar que, apesar dos entraves gerados pela legislação em vigor, o Brasil é vanguardista na regulação do regime de acesso à biodiversidade e a sua repartição de benefícios, situação que já lhe rendeu o bloqueio de patentes de espécies brasileiras por empresas estrangeiras no exterior e, ainda, o coloca em patamar diferenciado na implementação do Protocolo de Nagoia (MACHADO; GODINHO, 2011).

Nesse sentido, caminharemos na busca de alternativas que fortaleçam o arcabouço jurídico-institucional de proteção ambiental, de maneira geral, e da diversidade biológica, especificamente. Busca que se funda sobre a harmonização desses objetivos, sem que haja, por via reflexa, descaracterização de direito anteriormente tutelado. Assim, procuramos contribuir para o aprofundamento do modelo de sustentabilidade definido constitucionalmente, assegurando os direitos das futuras gerações, com base no princípio do não retrocesso ecológico.

\section{Espécies exóticas, biopirataria e biodiversidade}

Diante do contexto legislativo atual, marcado pela fragilidade em se garantir a perpetuidade do patrimônio genético do país, cumpre traçar, brevemente, os elementos que poderão contribuir para a inversão desse quadro.

Apenas a título de ilustração da monta de desafios existentes, destacamos que a biodiversidade, nos restringindo ao cenário nacional, vem sendo colocada em risco desde os tempos do "descobrimento", conforme destacam Machado e Oliveira (2009b, p. 23):

A introdução no Brasil de espécies exóticas vinculadas a atividades antrópicas, de forma intencional e/ou acidental, teve início com o processo de colonização das Américas pelos navegantes europeus. Desde então foram registradas espécies que se adaptaram e foram incorporadas à cultura nacional e às comunidades biológicas nativas, como o mexilhão Perna perna, assim como aquelas que se tornaram problemáticas para a saúde das populações, como o mosquito Aedes aegypti.

Entretanto, diante de um mundo globalizado e das suas exigências de celeridade nas trocas comerciais, as medidas preventivas podem acarretar prejuízo econômico em um mercado cada vez mais competitivo. Por isso, a "recomendação de se fazer a troca oceânica de água de lastro não é seguida pelos navios" (GOMES, 2004, p. 7). A introdução de espécies exóticas torna-se um exemplo marcante nesse contexto, visto que, segundo o sítio eletrônico da Agência Nacional de Transportes Aquaviários (ANTAQ), inúmeros são os impactos potenciais dessa atividade:

Durante a operação de lastreamento do navio, junto com a água também são capturados pequenos organismos que podem acabar sendo transportados e introduzidos em um outro porto previsto na rota de navegação. Teo- 
ricamente, qualquer organismo pequeno o suficiente para passar através do sistema de água de lastro pode ser transferido entre diferentes áreas portuárias no mundo. Isso inclui bactérias e outros micróbios, vírus, pequenos invertebrados, algas, plantas, cistos, esporos, além de ovos e larvas de vários animais. Devido à grande intensidade e abrangência do tráfego marítimo internacional, a água de lastro é considerada como um dos principais vetores responsáveis pela movimentação transoceânica e interoceânica de organismos costeiros.

As principais consequências negativas da introdução de espécies exóticas e nocivas incluem: o desequilíbrio ecológico das áreas invadidas, com a possível perda de biodiversidade; prejuízos em atividades econômicas utilizadoras de recursos naturais afetados e consequente desestabilização social de comunidades tradicionais; e a disseminação de enfermidades em populações costeiras, causadas pela introdução de organismos patogênicos (ANTAQ, 2011).

A Estratégia Nacional sobre Espécies Exóticas Invasoras está pronta desde dezembro de 2009, após elaboração participativa entre diversos setores da sociedade civil e do governo, na Câmara Técnica sobre Espécies Exóticas Invasora da Comissão Nacional de Biodiversidade (CONABIO). Desde então, se busca espaço político que a transforme em Decreto ou instrumento legal nacional, de maneira que atenda não só à dimensão dos problemas gerados ao país, mas principalmente à complexidade que é estabelecer ações e estratégias para controle, contenção e prevenção destas espécies nas linhas fronteiriças do Brasil. A Estratégia abarca a integração das diversas necessidades, que vão desde a confiabilidade do diagnóstico das espécies, avaliação de risco, identificação de competências técnico-científicas no país, até a gestão de sistema de informação e elaboração de planos de ação e, principalmente, a integração de todos os setores envolvidos nos processos de controle e prevenção. Determina a criação de Comitê Interministerial para Implementação da Estratégia Nacional, única maneira de vencer o emaranhado das atribuições legais de controle de entrada e circulação de espécies, pessoas e mercadorias no país.

Sua implementação é da maior relevância para o enfrentamento dos problemas e prejuízos causados ao país por estas espécies e, ainda, já traria avanços para o cumprimento das Metas de Aishi, ou as 20 Metas do Plano Estratégico 2011-2020, acordadas durante a Conferência das Partes (COP) 10 da Convenção sobre Diversidade Biológica (CDB) realizada em Nagoia, Japão, em 2010, a serem alcançadas até 2020 .

Além dessa questão, Barros-Platiau e Varella (1999) destacam a potencialidade da biopirataria ser praticada caso se tenha uma legislação muito severa, isso porque, atualmente, em toda a parte do mundo existem:

equipes de cientistas viajando pelo mundo em busca de material genético que possacontribuir para a elaboração de novos medicamentos ou melhoramentos genéticos. Se o Brasil impuser uma lei de acesso muito rígida, ou eles irão pesquisar emoutros países, ou tentarão coletar sem autorização oficial, o que caracteriza abiopirataria. O maior interesse para o desenvolvimento nacional é, na verdade, umgrande desafio: transformar toda biopirataria potencial em bioparceria (technology partnerships) para reforçar as capacidades tecnológicas do país (p. 83).

O desenvolvimento das "capacidades tecnológicas do país", conforme expressão usada pelos autores, requer não apenas uma legislação que opere como um instrumento milagroso para a imposição das normas de conduta ambientalmente sustentáveis, mas também o amadurecimento do setor de ciência e tecnologia para a biodiversidade e a consolidação de um pacto de cooperação entre sociedade, poder público e iniciativa privada para a melhoria e a perenidade das condições de existência humana.

Recentemente (29 de outubro de 2010), o Protocolo de Nagoia, aprovado na $10^{\mathrm{a}}$ Convenção das Partes (Secretariado da CDB, 2011), traz acordo mundial (embora ainda não estabelecido, pois precisa da ratificação de 50 países) para o acesso e a repartição justa e equitativa dos recursos genéticos e do conhecimento tradicional associados à biodiversidade (MACHADO; GODINHO, 2011). As bases do acordo estão centradas no reconhecimento mútuo das legislações nacionais e da informação e do conhecimento dos acessos e seus atores feitos nos países. Regras gerais estão dispostas, mas precisam ser detalhadas e adequadas às realidades nacionais. Há ainda a enorme demanda de capacitação de maneira ampla que deverá ser alcançada para o exercício pleno do acordo. Essa capacitação inclui não somente o próprio conhecimento da biodiversidade de cada país, seus sistemas de informação, gerenciamento de acessos e tipo de uso, mas principalmente a capacidade de proteger (não limitar ou impedir) os benefícios dela oriundos e mecanismos justos para transformar esses benefícios em riqueza nacional, desenvolvimento local e garantia da conservação de seus recursos genéticos. Neste sentido, há 
que se capacitar o país, a pesquisa, a produção nacional e as comunidades tradicionais no campo do direito internacional e de negócios da biodiversidade. Diante desta perspectiva, à biodiversidade deve acrescido valor tão expressivo quanto ao do pré-sal. E se dele os benefícios podem ser rapidamente extraídos, uma vez que houve investimento para que isso ocorresse no Brasil, o exemplo de sucesso pode ser estendido à biodiversidade.

O pacto de cooperação que se aponta deve se agregar à participação da sociedade na construção dos mecanismos nacionais e internacionais de atendimento ao Protocolo em construção e representa uma oportunidade única para o alinhamento da estrutura legal do país pró-protocolo e pró-desenvolvimento nacional.

Diante desse quadro, Moraes (2010, p. 7) destaca a participação dos cientistas no "processo de elaboraçãode políticas públicas ligadas àconservação de espécies ameaçadas de extinção, não apenas gerando informações que orientam decisões governamentais,como também mobilizando a sociedadee difundindo o respeito à natureza". Avulta-se, assim, o papel da sociedade, que, ao superar o impasse relacionado àescassez de recursos naturais, por meio de mudança em seu estilo, permitirá reverter "o quadro deperda de biodiversidade, rumo a umaeconomia mais sustentável" (MORAES, 2010, p. 7).

Essa mudança é possível dentro do arcabouço jurídico em vigor?

\section{Política nacional de biodiversidade}

Para que possamos embasar uma resposta à questão anterior, trataremos, nesta seção, dos aspectos jurídicos da política pública nacional de biodiversidade e sua relação com a responsabilidade intergeracional.

É preciso aprofundar esse debate no momento em que o Ministério do Meio Ambiente e entidades parceiras, visando aproveitar a relevância da Conferência das Nações Unidas sobre o Desenvolvimento Sustentável (Rio+20), consolidam propostas de vários setores para a construção da estratégia nacional para o alcance das Metas de Aichi ${ }^{4}$ (CIENTISTAS, 2011).
A discussão ganha ainda mais relevo quando se analisa de forma holística o cenário legislativo nacional, em que tramita a revisão do Código Florestal. Rodrigues (IMPACTOS, 2011) afirma, em relação à ocupação de áreas, que essa medida "desestimulará a proteção do meio ambiente", o que, "no médio e longo prazos, [trará] risco de impacto maior sobre as vegetações naturais dos biomas com prejuízos para a biodiversidade, conservação da água e do solo, entre outros serviços ambientais".

Esse pequeno paradoxo ilustra a ausência de uma visão holística da política ambiental no Brasil (BOEIRA, 2003; MACHADO, 2000). Isso porque, apesar de signatário da Convenção sobre Biodiversidade Biológica, reconhecida pelo Ministério das Relações Exteriores como um "dos principais resultados da Conferência das Nações Unidas para o Meio Ambiente e o Desenvolvimento - CNUMAD (Rio 92)" e como um dos "mais importantes instrumentos internacionais relacionados ao meio ambiente" (BRASIL, 2011), persistem discussões, como a do novo Código Florestal, que podem ter resultado oposto aos ideais de proteção do patrimônio genético brasileiro. Se, por um lado, enquanto país, temos uma atuação expressiva e de liderança em políticas internacionais para a biodiversidade, indicando claramente a sustentabilidade como ferramenta de combate à pobreza, por outro, executamos a política e o planejamento interno como se as desconhecêssemos.

Apesar de encontrarem amparo no Decreto $\mathrm{n}^{\circ} 4.339$, de 22 de agosto de 2002, cujo anexo apresenta a Política Nacional de Biodiversidade, em grande parte baseada na Convenção sobre Biodiversidade Biológica, os princípios da prevenção e da precaução carecem de regulamentação específica para que possam instrumentalizar, efetivamente, a proteção intertemporal da diversidade biológica do país.

Nesse sentido, o objetivo geral da Política Nacional de Biodiversidade deve ser entendido como o de promover, "de forma integrada, a conservação da biodiversidade e a utilização sustentável de seus componentes, com a repartição justa e equitativa [entre as presentes e futuras gerações] dos benefícios derivados da utilização dos recursos genéticos, de componentes do patrimônio genético e dos conhecimentos tradicionais associados a esses recursos" (art. $5^{\circ}$, Decreto $\mathrm{n}^{\circ} 4.339 / 2002$ ).

\footnotetext{
${ }^{4}$ Acordo global entre 193 países que, ao lado do Protocolo de Nagoia, são considerados "os compromissos mais urgentes a serem cumpridos" para a preservação da biodiversidade (LINO, 2011, p. 9). O Protocolo de Acesso e Repartição de Benefícios Advindos da Biodiversidade, ou Protocolo de Nagoia, foi assinado em 29 de outubro de 2010 "para mudar o cenário de biopirataria e exploração da riqueza natural por quem detém capital e tecnologia sem dividir o resultado com as sociedades dos locais de origem [e] precisa da ratificação de 50 países para entrar em vigor, mas ainda não foi ratificado por nenhum“ (LEMLE, 2011).
} 
Assim sendo, os artigos $2^{\circ}$ e $4^{\circ}$ do referido Decreto, além de conter os princípios mencionados anteriormente, indicam objetivos específicos que caminham ao encontro da proposta aqui discutida:

Art. $2^{\circ}$, XVIII - a pesquisa, a conservação ex situ e a agregação de valor sobre componentes da biodiversidade brasileira devem ser realizadas preferencialmente no país, sendo bem-vindas as iniciativas de cooperação internacional, respeitados os interesses e a coordenação nacional;

Art. $4^{\circ}$, II - o esforço nacional de conservação e a utilização sustentável da diversidade biológica deve ser integrado em planos, programas e políticas setoriais ou intersetoriais pertinentes de forma complementar e harmônica;

Art. $4^{\circ}$, III - investimentos substanciais são necessários para conservar a diversidade biológica, dos quais resultarão, conseqüentemente, benefícios ambientais, econômicos e sociais (Decreto ${ }^{\circ}$ 4.339/2002).

Defendemos, a partir da leitura desses dispositivos, que a Política Nacional de Biodiversidade deve ser, juntamente com a Constituição Federal e Política Nacional de Meio Ambiente, utilizada como substrato das discussões relacionadas às mudanças do Código Florestal e de toda e qualquer regulamentação que implique em real ou potencial redução ou perda de biodiversidade.

A integração entre as diversas políticas setoriais deve tomar por fio condutor a dignidade da pessoa humana das presentes e futuras gerações que, em relação ao tema em pauta, refere-se à implementação de arcabouço protetivo do patrimônio genético brasileiro. Arcabouço este que pressupõe um profundo mapeamento técnico-científico da diversidade biológica brasileira e da definição dos espaços territoriais significativos a serem protegidos para a conservação da natureza. ${ }^{5}$

Valemo-nos da ressalva de Berlinck (2011) para relevar que "as iniciativas de pesquisa e conservação da biodiversidade brasileira devem ser intensificadas e aprofundadas, para que se possa realmente valorizar um dos maiores e mais importantes patrimônios nacionais".

Sobressai dessa análise a importância da aplicação dos royalties do petróleo para a conservação da biodiver- sidade nacional, finalidade que se coaduna à promoção da justiça intergeracional incutida na gênese daquela compensação financeira.

Para tanto, uma das alternativas é a definição de percentual dos royalties para o Programa Nacional da Diversidade Biológica - PRONABIO, instituído pelo Decreto $\mathrm{n}^{\circ} 4.703$, de 21 de maio de 2003, e que possui uma estrutura básica que compreende:

I - componentes temáticos:

a) conhecimento da biodiversidade;

b) conservação da biodiversidade;

c) utilização sustentável dos componentes da biodiversidade;

d) monitoramento, avaliação, prevenção e mitigação de impactos sobre a biodiversidade;

e) acesso aos recursos genéticos e aos conhecimentos tradicionais associados e repartição de benefícios;

f) educação, sensibilização pública, informação e divulgação sobre biodiversidade;

g) fortalecimento jurídico e institucional para a gestão da biodiversidade;

II - conjunto de biomas:

a) Amazônia;

b) Cerrado e Pantanal;

c) Caatinga;

d) Mata Atlântica e Campos Sulinos;

e) Zona Costeira e Marinha(Decreto $n^{\circ}$

4.703/2003).

Moraes (2010, p. 6), ao comparar um aumento de $78 \%$ na "demanda humana por recursos e serviços ambientais [...] ao longo dos últimos 30 anos no planeta" com uma diminuição de $30 \%$ nas populações de vertebrados, apresenta o patente descompasso entre as necessidades humanas e as possibilidades do planeta em suportar essa pressão antrópica ilimitada. Diante do cenário brasileiro de espécies ameaçadas de extinção, o autor referenda que a "capacidade das instituições públicas e privadas depende da velocidade de geração e processamento das informações

\footnotetext{
5 Conservação da natureza entendida como "o manejo do uso humano da natureza, compreendendo a preservação, a manutenção, a utilização sustentável, a restauração e a recuperação do ambiente natural, para que possa produzir o maior benefício, em bases sustentáveis, às atuais gerações, mantendo seu potencial de satisfazer as necessidades e aspirações das gerações futuras, e garantindo a sobrevivência dos seres vivos em geral” (art. $2^{\circ}$, II, Lei 9.998/2000).
} 
científicas, assim como da adoção de protocolos que levem em conta o contexto sociopolítico, o elevado número de espécies tropicais e a necessidade do estabelecimento de metas objetivas de ação" (MORAES, 2010, p. 7).

Em reportagem do Jornal da Ciência, Luiz Merico, coordenador nacional da União Internacional para a Conservação da Natureza (UICN), alerta que o "Brasil precisa criar um marco regulatório para cumprir integralmente as metas do acordo internacional para 2020 [Metas de Aichi] sobre a conservação e uso da biodiversidade" (MONTEIRO, 2011). Merico (apud MONTEIRO, 2011) afirma, por fim, que as metas precisam ser definidas e também institucionalizadas por meio de políticas públicas, com o devido monitoramento.

De maneira semelhante, Moraes (2010, p. 6-7) destaca a necessidade das metas e, ainda, de se consolidar mecanismos político-administrativos mais eficientes e dinâmicos, que viabilizem a redução das atuais taxas de extinção.

A partir do que foi até aqui exposto, propomos, para discussão e aprofundamento em relação ao fortalecimento das políticas públicas de proteção do patrimônio genético brasileiro, 11 diretrizes básicas: 1) Legislação e mecanismos de cumprimento adequados para regulamentação do acesso aos recursos genéticos; 2) Legislação de proteçãodo conhecimento da biodiversidade oriundo das comunidades tradicionais e povos indígenas; 3) Harmonização com o arcabouço legislativo ambiental em vigor (Política Nacional do Meio Ambiente, Sistema Nacional de Unidades de Conservação, Política Nacional de Plantas Medicinais...); 4) Definição de fontes de recursos (p. ex.: royalties do petróleo); 5) Investimentos em pesquisa científica e desenvolvimento tecnológico; 6) Investimentos na capacidade de gestão da promoção do uso e da repartição dos benefícios da biodiversidade; 7) Contínuo levantamento do patrimônio genético brasileiro; 8) Definição de estratégias específicas e transversais para a conservação da biodiversidade; 9) Institucionalização das metas no arcabouço jurídico-administrativo; 10) Criação de instrumentos específicos para monitoramento e acompanhamento das metas; e 11) Sistema nacional de informações sobre a diversidade biológica.

\section{Considerações finais}

Ao término desse trabalho, esperamos ter contribuído para a promoção da integração do desenvolvimento sustentável com os campos econômico, social e ambiental por meio da análise e discussão das potencialidades de aplicação dos royalties do petróleo na conservação da biodiversidade brasileira.

Constatamos que o cenário nacional da biodiversidade nos parece o retrato da constatação de que o "futuro já foi moldado (dentro de largos limites) por decisões tomadas no passado ou que estão sendo tomadas agora visando a objetivos a curto prazo" (FURTADO, 1975, p. 70). Assim, os erros do passado são repetidos e não superados. Por conta desse traço estruturante da realidade nacional, procuramos levantar as discussões acerca do aprimoramento e da implementação, no presente, de medidas de longo prazo possíveis e viáveis para que se prolongue a biodiversidade do planeta. Ao discutirmos o arcabouço institucional-legal da política de biodiversidade, tentamos contribuir com uma estratégia, talvez não original, mas certamente particularizada, para o desenvolvimento sustentável. O pressuposto de nossa ação está assentado na avaliação de Sachs (1975, p. 62) de que a "história nunca oferece modelos que possam ser imitados. Ela nos dá antimodelos que devem ser superados".

Nesse sentido, a nossa proposta pretende colaborar para a edificação de um modelo participativo de política pública voltado para o planejamento de longo prazo, de maneira geral e, especificamente, para a proteção da biodiversidade. Procuramos fornecer elementos para a superação das lacunas apresentadas com a finalidade de fortalecer o debate para a definição de parâmetros capazes de equilibrar a demanda econômica com as possibilidades ambientais e as necessidades intergeracionais.

Mesmo diante das várias opções existentes para a aplicação dos royalties do petróleo, procuramos demonstrar não apenas a relevância de uma linha específica para a proteção da biodiversidade, mas tambémque se trata de uma finalidade relacionada à própria gênese dessa compensação para com as gerações futuras. Assim sendo, acreditamos ter sido possível ampliar a discussão acerca da destinação dos royalties, para a qual asseveramos a natureza democrática e participativa do debate sediado no modelo de sustentabilidade, e com vistas a contribuir para a construção de um projeto de Estado socialmente justo, economicamente distributivo, ambientalmente saudável e intergeracionalmente responsável.

Enfim, diante das discussões acerca da destinação dos royalties, somos da opinião que a aplicação de percentual desses recursos na preservação da biodiversidade configura elemento compatível com a gênese de uma compensação financeira que se propõe instrumento de promoção de justiça intergeracional. 


\section{Referências}

ACSELRAD, H. Sentidos da sustentabilidade humana. In: . (Org.). A duração das cidades: sustentabilidade e risco nas políticas urbanas. Rio de Janeiro: DP\&A, 2001. p. 27-55.

ALMEIDA, D. C. A fundamentalidade dos direitos sociais e o princípio da proibição de retrocesso. Inclusão Social, Brasília, v. 2 , n. 1, p. 118-124, mar. 2007.

ANTAQ - AGÊNCIA NACIONAL DE TRANSPORTES AQUAVIÁRIOS. Meio Ambiente-Água de Lastro. Disponível em: <http://www.antaq.gov.br/portal/MeioAmbiente_AguaDeLastro.asp >. Acesso em: 08/11/2011.

ANTUNES, P. B. Dano ambiental: uma abordagem conceitual. Rio de Janeiro: Lúmen Júris, 2002.

AZEVEDO, C. M. A. A regulamentação do acesso aos recursos genéticos e aos conhecimentos tradicionais associados no Brasil. Biota Neotropica,Campinas, v.5, n.1, p. 19-27, 2005.

BERLINCK, R. A importância da biodiversidade brasileira. Jornal da Ciência, n. 4382, 10 nov. 2011. Disponível em: $<$ http://www.jornaldaciencia.org.br/Detalhe.jsp?id=80057>. Acesso em: 20/11/2011.

BARROS-PLATIAU, A. F.; VARELLA, M. D. Acesso aos recursos genéticos, transferência de tecnologia e bioprospecção. Revista Brasileira de Política Internacional, Brasília, v.42, n.2, p. 81-98, jul./dez. 1999.

BOEIRA, S. L. Política e gestão ambiental no Brasil: da Rio-92 ao Estatuto da Cidade. Revista Alcance, v. 10, n. 3, p. 525-558, set./dez. 2003.

BRASIL. Ministério de Minas e Energia. Plano Nacional de Energia 2030. Brasília: MME/EPE, 2007.

. Ministério das Relações Exteriores. Convenção sobre Biodiversidade Biológica. Disponível em: <http://www.cdb. gov.br/CDB>. Acesso em: 18/11/2011.

CAMARGO, A.; CAPOBIANCO, J. P. R.; OLIVEIRA, J. A. P. Como fazer com que o acesso aos recursos genéticos da biodiversidade brasileira seja feito de forma ambientalmente sustentável e seus benefícios repartidos de forma socialmente justa? In: (Orgs.). Meio ambiente Brasil: avanços e obstáculos pós-Rio-92. Rio de Janeiro: FGV, 2002. p. 245-248.

CARNEIRO, E. J. Política ambiental e a ideologia do desenvolvimento sustentável. In: ZHOURI, A.; LASCHEFSKI, K.;
PEREIRA, D. B. (Orgs). A insustentável leveza da politica ambiental: desenvolvimento e conflitos socioambientais. Belo Horizonte: Autêntica, 2005. p. 27-47.

CARNEIRO, R. Direito Ambiental: uma abordagem econômica. Rio de Janeiro: Forense, 2003.

CARVALHO, E. F. Meio ambiente \& direitos humanos. Curitiba: Juruá, 2005.

CIENTISTAS participam de diálogos sobre a biodiversidade em Brasília. Jornal da Ciência, n. 4386, 17 nov. 2011. Disponível em: <http://www.jornaldaciencia.org.br/Detalhe. jsp?id=80132>. Acessoem: 18/11/2011.

CONVENTION ON BIOLOGICAL DIVERSITY.Nagoya Protocol on Access to Genetic Resources and the Fair and Equitable Sharing of Benefits. Protocols, etc., 2010 Oct. 29. II. Conference of the Parties to the Convention on Biological Diversity (2010: Nagoya, Japan). III. United Nations. K3488 .A48 2011. Disponível em: <http://www.cbd.int/abs/doc/ protocol/nagoya-protocol-en.pdf $>$. Acessoem: 22/11/2011.

FARZIN, Y. H. Can an exhaustible resource economy be sustainable? Social Science Research Network, 2002. Disponível em: <http://papers.ssrn.com/sol3/papers.cfm?abstract $\mathrm{id}=317933>$. Acesso em: 02/12/2008.

FONSECA, I.; BURSZTYN, M. A banalização da sustentabilidade: reflexões sobre governança ambiental em escala local. Sociedade e Estado, Brasília, v. 24, n. 1, p. 17-46, jan./ abr. 2009.

FREITAS, P. S. Rendas do petróleo, questão federativa e instituição de fundo soberano. Textos para discussão, Brasília, n. 53, fev.2009. Brasília: Senado Federal: Centro de Estudos. p. 1-56.

FURTADO, C. Meioambiente, desenvolvimento e subdesenvolvimento na Teoria Econômica do Planejamento. In: ANDRADE, M. C. et al. Meioambiente, desenvolvimento e subdesenvolvimento. São Paulo: Hucitec, 1975. p. 67-90.

GODINHO, R. S.; MACHADO, C.J.S. Avanços e percalços na elaboração da legislação nacional sobre acesso a recursos genéticos e aos conhecimentos tradicionais associados.RevistaDesenvolvimento e MeioAmbiente, v. 24, 2011 [no prelo].

GOMES, A. P. Água de lastro. Diretoria de Portos e Costa, 2004. Disponível em: <https://www.dpc.mar.mil.br/epm/ portuarios/Santos_AnaPaula.pdf $>$.Acesso em: 08/11/2011. 
IMPACTOS de médio e longo prazo para a biodiversidade preocupam cientistas.Jornal da Ciência, n. 4386, 17 nov. 2011. Disponível em: <http://www.jornaldaciencia.org.br/Detalhe. jsp?id=80132 $>$. Acesso em: 18/11/2011.

INSTITUTO SOCIOAMBIENTAL - ISA. Povos indígenas no Brasil. Disponível em: <http://pib.socioambiental.org/pt>. Acesso em: 10/09/2010.

JUNGBLUT, C. et al.Senado aprova proposta de divisão de royalties que prejudica Rio e ES. O Globo, Rio de Janeiro, 20 out. 2011. Economia, p. 32.

KISS, A.; SHELTON, D. Guide to International Environmental Law. Leiden: Martinus Nijhoff, 2007.

LEAL, J. A.; SERRA, R. Uma investigação sobre os critérios de repartição dos royalties petrolíferos. In: PIQUET, R. (Org.). Petróleo, royalties e região. Rio de Janeiro: Garamond, 2003. p. 163-184.

LEIS, H. R. A modernidade insustentável: as críticas do ambientalismo à sociedade contemporânea. Petrópolis: Vozes; Santa Catarina: UFSC, 1999.

LEMLE, M. Fiocruz debate desafios do Protocolo de Nagoia. Disponível em: $<$ http://www.fiocruz.br/vpaaps/cgi/cgilua.exe/ sys/start.htm?infoid=41\&sid=38>. Acesso em: 20/11/2011.

LENZI, C. L. Sociologia ambiental: risco e sustentabilidade na modernidade. Bauru: EDUSC, 2006.

LEROY, J.; PACHECO, M. E. L. Como fazer com que o acesso aos recursos genéticos da biodiversidade brasileira seja feito de forma ambientalmente sustentável e seus benefícios repartidos de forma socialmente justa? In: CAMARGO, A.; CAPOBIANCO, J. P. R.; OLIVEIRA, J. A. P. (Orgs.). Meio ambiente Brasil: avanços e obstáculos pós-Rio-92. Rio de Janeiro: FGV, 2002. p. 249-252.

LEWINSOHN, T. M.; PRADO, P. I. Quantas espécies há no Brasil? Megadiversidade, v. 1, n. 1, p. 36-42, 2005.

LINO, F. C. Convenção da diversidade biológica: metas de Aichi 20: protocolo de Nagoia. São Paulo: Conselho Nacional da Reserva da Biosfera da Mata Atlântica, 2011.

MACHADO, C. J. S. A questão ambiental brasileira: uma análise sociológica do processo de formação do arcabouço jurídico-institucional. Revista de Estudos Ambientais, Blumenau, v. 2, n. 2/3, p. 5-20, 2000.

. (Org.). Ciências, políticas públicas e sociedade sustentável. Rio de Janeiro: E-Papers, 2012. No prelo.
; GODINHO, R. S. Dinâmica e características do processo brasileiro de regulação do acesso à diversidade biológica e aos conhecimentos tradicionais associados, Revista de Informação Legislativa, n. 191, p. 97-125, 2011.

; OLIVEIRA, A. E. S. Recomendações para elaboração e consolidação de uma estratégia nacional de prevenção e controle das espécies exóticas no Brasil. Ciência e Cultura, v. 61, p. 42-45, 2009a.

Espécies exóticas invasoras: problema nacional ainda pouco conhecido. Ciência e Cultura, Campinas, v. 61, p. 23-26, 2009 b.

MAY, P. H.; MOTTA, R. S. Introdução. In: (Orgs.).Valorando a natureza: análise econômica para o desenvolvimento sustentável. Rio de Janeiro: Campus, 1994.

MINARÉ, R. Regulamentação do acesso a recursos genéticos: entre um Executivo inoperante e um Legislativo omisso. Portal LFG: 04 jul. 2008.Disponível em: <http://www.lfg.com.br/ artigo/20080704114802291_biodireito-regulamentacao-do-acesso-a-recursos-geneticos-entre-um-executivo-inoperante-e-um-legislativo-omisso-reginaldo-minare.html >. Acesso em: 08/11/2011.

MIOZZO, P. C. O princípio da proibição do retrocesso social e sua previsão constitucional: uma mudança de paradigma no tocante ao dever estatal de concretização dos direitos fundamentais no Brasil. Florianópolis: E-Governo/UFSC, 2011. Disponível em: <http://www.egov.ufsc.br/portal/conteudo/o-princ $\% \mathrm{C} 3 \% \mathrm{ADpio}$-da-proibi $\% \mathrm{C} 3 \% \mathrm{~A} 7 \% \mathrm{C} 3 \% \mathrm{~A} 30$-do-retrocesso-social-e-sua-previs $\% \mathrm{C} 3 \% \mathrm{~A} 3 \mathrm{o}$-constitucional-uma-mudan\%C3\%A7a-de->. Acesso em: 02/11/2011.

MONTEIRO, V. União Internacional vê necessidade de criar legislação para conservar biodiversidade do Brasil. Jornal da Ciência, n. 4382, 10 nov. 2011. Disponível em: <http://www. jornaldaciencia.org.br/Detalhe.jsp?id=80052 >. Acesso em: 20/11/2011.

MONTIBELLER FILHO, G. O mito do desenvolvimento sustentável: meio ambiente e custos sociais no moderno sistema produtor de mercadorias. Florianópolis: UFSC, 2004.

MORAES, M.A. Até que ponto a ciência pode contribuir para a conservação da diversidade biológica? Ciência e Cultura, Campinas, v. 62, n. 3, p. 6-7, 2010.

OLIVEIRA. J. C. Adiada a votação do veto à regra de divisão de royalties do petróleo. Agência Câmara de Noticias, Brasília, 20 out. 2011. Disponível em: <http://www2.camara. gov.br/agencia/noticias/ECONOMIA/204270-ADIADA- 
-A-VOTA $\%$ C3\%87\%C3\%83O-DO-VETO- $\%$ C3\%80-REGRA-DE-DIVIS\%C3\%83O-DE-ROYALTIES-DO-PETR\%C3\%93LEO.html>. Acessoem: 23/10/2011.

OSORIO, L. A. R.; LOBATO, M. O.; CASTILLO, X. A. Debates on sustainable development: towards a holistic view of reality. Environment, Development and Sustainability, v. 7, n. 4, p. 501-518, dez. 2005.

PACHECO, C. A. G. O impacto dos royalties do petróleo no desenvolvimento econômico dos municípios da região norte fluminense. In:CONGRESSO BRASILEIRO DE P\&D EM PETRÓLEO E GÁS, 3., Salvador, out. 2005. Anais eletrônicos... Disponível em: <www.portalabpg.org.br/PDPetro/3/trabalhos/ IBP0181_05.pdf>. Acesso em: 24/07/2008.

PETROBRAS. A Petrobras: Bacia de Campos. Disponível em: <http://www2.petrobras.com.br/petrobras/portugues/ plataforma/pla_bacia_campos.htm>. Acesso em: 13/09/2010.

PIQUET, R. Da cana ao petróleo: uma região em mudança. In: PIQUET, R. (Org.). Petróleo, royalties e região. Rio de Janeiro: Garamond, 2003. p. 219-238.

PNUMA.Rumo a uma economia verde: caminhos para o desenvolvimento sustentável e a erradicação da pobreza. UNEP, 2011. Disponível em: <www.unep.org/greeneconomy >. Acesso em: 02/11/2011.

POSTALI, F. A. S. Regime fiscal, investimento em petróleo e opções reais. Economia Aplicada, Ribeirão Preto, v. 13, n.2, p. 207-230, abr./jun.2009.

PRUDENTE, A. S. Hidrelétrica Belo Monte: manifesta agressão ao princípio daproibição do retrocesso ecológico. $C E J$, Brasília, n. 51, p. 33-40, out./dez. 2010.

RIBEIRO, W. C. Em busca da qualidade de vida. In: PINSKY, J.; PINSKY, C. B. (Orgs.). História da cidadania. São Paulo: Contexto, 2003. p. 399-417.

ROMEIRO, A. R. Economia ou economia política da sustentabilidade. In: MAY, P. H.; LUSTOSA, M. C.; VINHA, V. (Orgs.). Economia do meio ambiente. Rio de Janeiro: Elsevier, 2003. p. 1-29.
SACHS, I. Meioambiente e desenvolvimento: estratégias de harmonização. In: ANDRADE, M. C. et al. Meio ambiente, desenvolvimento e subdesenvolvimento. São Paulo: Hucitec, 1975. p. 45-63.

SENADO FEDERAL. Atividade Legislativa: PLS - Projeto de Lei do Senado n. 306, de 1995. Disponível em: <http:// www.senado.gov.br/atividade/Materia/Detalhes.asp?p_cod_ mate $=1691>$. Acesso em: 08/11/2011.

SERRA, R. Concentração espacial das rendas petrolíferas e sobrefinanciamento das esferas de governo locais. In: PIQUET, R.; (Orgs.). Petróleo e região no Brasil: o desafio da abundância. Rio de Janeiro: Garamond, 2007. p. 77-110.

STRECK, L. L. Hermenêutica jurídica e(m) crise: uma exploraçãohermenêutica da construção do Direito. Porto Alegre: Livraria do Advogado, 2003.

SZPILMAN, M. Biodiversidade - As nações mais ricas em diversidade do planeta. Informativo Instituto Ecológico Aqualung, n. 20 - jul./ago. 1998. Disponível em: <http:// www.institutoaqualung.com.br/info_biodiversidade23.html . Acesso em: 19/11/2011.

TRINDADE, A. A. C. Direitos humanos e meio ambiente: paralelo dos sistemas de proteção ambiental. Porto Alegre: Sergio Antonio Fabris, 1993.

UNITED NATIONS. Our Common Future. Chapter 2: towards sustainable development. Disponível em: $<\mathrm{http}$ ://www.undocuments.net/ocf-02.htm>. Acesso em: 24/11/2008.

VARELLA, M. D. Biodiversidade: o Brasil e o quadro internacional. Revista Brasileira de Política Internacional, Brasília, v. 40, n. 1, p. 123-141, jan./jun. 1997.

VEIGA, J. E. Desenvolvimento sustentável: o desafio do século XXI. Rio de Janeiro: Garamond, 2006.

WESSENDORF, K. (Ed.). The indigenous world 2008. Copenhagen: International Work Group for Indigenous Affairs, 2008 .

Recebido em janeiro de 2012 Aceito em maio de 2012. Publicado em junho de 2012. 